\title{
FILANTROPI BERBASIS FAITH BASED ORGANIZATION DI INDONESIA (Studi Kasus Program PKPU)
}

\author{
Amril Maryolo. AR \\ Mahasiswa Pascasarjana UIN Sunan Kalijaga Yogyakarta \\ E-mail: amril_maryolo@yahoo.com
}

\begin{abstract}
Philanthropy is an act of generosity that has a sense of sympathy for human beings. Generosity is an integral part of the character of Indonesian society, derived from religious wisdom, culture, and a strong sense of community. The existence of Faith Based Organization (religious-based organization) helps the government in overcoming the social inequalities that occur in middle and lower society. One of the humanitarian organizations based on Islam in Indonesia is the Post of Justice Peduli Ummat (PKPU) which provides assistance, various forms of social activities in various fields. The presence of these humanitarian agencies in Indonesia marks the "new practice of philanthropy" of the Islamic philanthropy movement in realizing the public welfare.
\end{abstract}

Keywords : Philantrophy, Faith Based Organization,PKPU

\begin{abstract}
Abstrak
Filantopi merupakan tindakan kedermawanan yang memiliki rasa simpati terhadap sesame manusia. Sikap kedermawanan merupakan bagian integral dari karakter masyarakat Indonesia, berasal dari kearifan religius, budaya, dan rasa yang kuat dalam masyarakat. Keberadaan Faith Based Organization (organisasi berbasis keagamaan) membantu pemerintah dalam mengatasi kesenjangan sosial yang terjadi di masyarakat menengah kebawah. Salah satu organisasi kemanusiaan berbasis agama Islam di Indonesia adalah Pos Keadilan Peduli Ummat (PKPU) yang memberikan bantuan, berbagai bentuk kegiatan sosial di berbagai bidang. Kehadiran lembaga-lembaga kemanusiaan tersebut di Indonesia menandai "praktek baru kedermawanan"gerakan filantropi Islam dalam mewujudkan kesejahteraan publik.
\end{abstract}

Kata kunci : Filantropi, Organisasi Berbasis Keagamaan, PKPU

\section{PENDAHULUAN}

Filantropi adalah sikap kedermawanan yang berwujud tindakan yang mencintai sesama manusia serta nilai kemanusiaan, sehingga menyumbangkan harta, waktu, dan tenaganya untuk membantu orang lain. Aktivitas filantropi tidak hanya dari pribadi manusia namun juga organisasiorganisasi sosial-keagamaan, termasuk Nahdatul Ulama dan Muhammadiyah, sejak awal 1990-an telah menjadi bagian dari masyarakat sipil. Ketika negara kurang berperan memberikan layanan dan bantuan sosial kepada masyarakat meskipun telah ada regulasi yang telah mengaturnya, hal tersebut yang mendorong organisasi sukarelawan.

Organisasi filantropi Islam di Indonesia secara aktif terlibat dalam berbagai jenis proyek sosial untuk melayani masyarakat miskin serta 
mendalami dampak terhadap wacana muslim tentang masalah kesejahteraan. Tujuan organisasi tersebut untuk memberikan pembinaan keadilan sosial dan memperbaiki kesejahteraan masyarakat, menyediakan bantuan bagi mereka yang membutuhkan termasuk keluarga yang berpenghasilan rendah, anak yatim, korban bencana, dan pengungsi yang terkena dampak bencana. Aktivisme filantropis muncul sebagai respon ketidakcukupan negara dalam mempertahankan sistem kesejahteraan dan mengurangi penderitaan. Relasi organisasi sukarelawan dan filantropi dengan negara ditandai dengan kolaborasi, tumpang tindih, dan interdependensi. Oleh karena itu, organisasi sukarelawan melengkapi agenda berbasis negara kesejahteraan. Dari perspektif politik, kebijakan filantropi negara Islam menunjukkan bahwa negara difasilitasi muslim sebagai bentuk aspirasi agama dan politik. Bentuk filantropi dari negara Muslim adalah prioritas filantropi zakat untuk melindungi kelompok kurang mampu termasuk golongan minoritas. ${ }^{1}$

Pos Keadilan Peduli Umat (PKPU) merupakan salah satu dari sekian banyak lembaga filantropi berbasis faith based organization (organisasi berbasis keagamaan) di Indonesia. Lembaga ini berkomitmen dalam rangka memberikan fasilitas antara kaum dermawan (aghniya) dengan fakir miskin (dhuafa). Awal perkembangan PKPU hanya mengelola dan mendistribusikan dana umat yang sumbernya dari zakat, infaq, dan shadaqah. Namun perkembangannya, hingga saat ini PKPU menerima donasi dalam hal bantuan kemanusiaan dunia, peningkatan pengetahuan dan keterampilan anak yatim, pemberdayaan potensi dan kapasitas masyarakat, dan pemberdayaan kualitas hidup untuk kesejahteraan masyarakat. Kehadiran PKPU memberikan dampak positif bagi kualitas pembangunan manusia serta perkembangan di bidang ekonomi, kesehatan, pendidikan, dan tanggap darurat yang merupakan fokus pada lembaga tersebut.

Tulisan ini akan memfokuskan pada program PKPU yang merupakan lembaga filantropi berbasis keagamaan yang berorientasi pada kesejahteraan sosial. PKPU menjadi pihak yang turut memberikan bantuan kepada masyarakat yang membutuhkan bantuan tidak hanya dalam skala nasional tetapi juga skala internasional. Islam menekankan pentingnya hubungan sesama manusia (habluminannas) sebagai kepedulian berbagi atau menawarkan apa saja kepada orang yang membutuhkan serta negara mewajibkan memberikan bantuan kepada fakir miskin agar keadilan sosial mampu terwujud. Berikut penulis akan menjelaskan mengenai, pertama, bagaimana relasi Islam dengan filantropi berbasis faith based organization. Kedua, prospek filantropi berbasis keagamaan. Ketiga, filantropi dalam

${ }^{1}$ Amril Maryolo AR, "Review artikel Hilman Latief (Philantrophy and Muslim Citizenship in Post-Suharto Indonesia)", Tugas review artikel dalam mata kuliah Topik Khusus Agama dan Masyarakat di Pps UIN Sunan Kalijaga Yogyakarta, tanggal 21 November 2016, 1. 
mewujudkan kesejahteraan sosial dan keadilan sosial. serta keempat, program PKPU sebagai lembaga filantropi dan transformasi gerakan PKPU dalam pemberdayaan ummat.

\section{ISLAM, FAITH BASED ORGANIZATION, DAN FILANTROPI}

Islam menaruh perhatian yang sangat serius terhadap filantropi. Praktek filantropi telah diatur dalam Islam sebab hal ini merupakan wujud habluminanas (hubungan antar manusia). Islam seperti agama-agama lainnya, mengajarkan nilai kesukarelaan dalam arti kepedulian berbagi dengan orang lain atau menawarkan apa saja kepada mereka yang membutuhkan. Salah satu dari aturan Islam yang mengatur sikap kedermawanan dan nilai-nilai kemanusiaan adalah zakat, infaq, dan sadaqah.

Islam memberikan landasan moral bagi regenerasi sipil. Iman memberikan makna pada pelayanan masyarakat dan niat baik, penempatan hubungan spiritual antara individu dan isu publik. Islam sangat membantu untuk internalisasi orientasi kepada kepentingan publik. ${ }^{2}$ Program berbasis keagamaan yang mulai di munculkan oleh Islam untuk membantu mereka yang membutuhkan. Kegiatan ini bertujuan untuk meningkatkan taraf hidup kaum miskin di Indonesia karena organisasi filantropi berbasis keagamaan sangat dipercaya oleh masyarakat dalam pengentasan masalah kemiskinan secara serius.

Dalam pandangan Islam telah jelas bahwa Islam menolak teori kapitalisme yang melakukan akumulasi kapital dan bebas memberikan hartanya kepada siapa saja yang dia kehendaki, bebas melakukan tabungan, dan menghaburkan untuk aktivitas tertentu. Ia telah mengingkari kekuasaan Allah dan merampas hak milik rakyatnya. ${ }^{3}$

Allah berfirman dalam Surah An-Nur Ayat 33 :

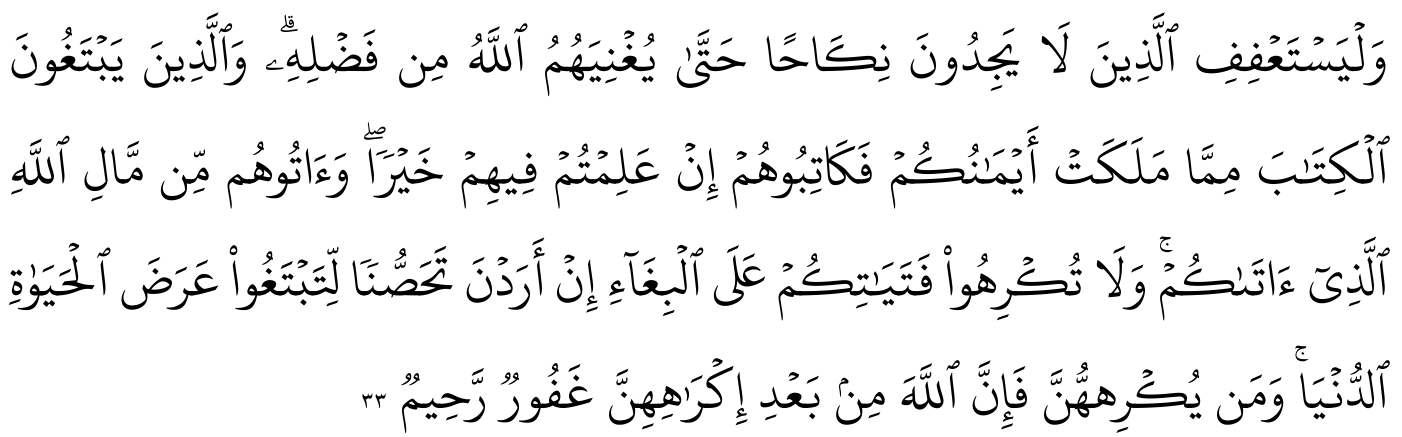

Terjemahan :

" Dan orang-orang yang tidak mampu kawin hendaklah menjaga kesucian (diri)nya, sehingga Allah memampukan mereka dengan karunia-Nya. dan

${ }^{2}$ Hilman Latief, Politik Filantropi Islam di Indonesia (Yogyakarta: Ombak, 2013), xiv.

${ }^{3}$ Muhammad Yusuf Al-Qardhawi, Musykilatul Fakri Wa-Kaifa 'Alajahal Islam, terj. Umar Fanany. (Surabaya: Bina Ilmu, 1996), 38-39. 
budak-budak yang kamu miliki yang memginginkan perjanjian, hendaklah kamu buat Perjanjian dengan mereka, jika kamu mengetahui ada kebaikan pada mereka, dan berikanlah kepada mereka sebahagian dari harta Allah yang dikaruniakan-Nya kepadamu. dan janganlah kamu paksa budak-budak wanitamu untuk melakukan pelacuran, sedang mereka sendiri mengingini kesucian, karena kamu hendak mencari Keuntungan duniawi. dan Barangsiapa yang memaksa mereka, Maka Sesungguhnya Allah adalah Maha Pengampun lagi Maha Penyayang (kepada mereka) sesudah mereka dipaksa itu."

Karena itu, Allah mewajibkan orang kaya untuk mengeluarkan "hak tertentu" dari kekayaan mereka. Dengan cara itu bisa dijamin mengatasi persoalan sosial dan kemiskinan.

Menurut Dawam Rahardjo, praktik filantropi sesungguhnya telah ada sebelum Islam mengingat wacana keadilan sosial juga telah berkembang. ${ }^{4}$ Menurut Warren Weaver, menegaskan bahwa filantropi bukanlah tradisi yang baru melainkan telah ada pada masa kuno. ${ }^{5}$ Praktik ini tidak hanya dalam agama Islam tetapi juga dalam agama-agama lain, seperti Hindu, Budha, Kristen, dan lain-lain.

Dalam masyarakat Barat dikenal konsep kedermawanan individu (private charity), aspek ini mempunyai perbedaan secara konseptual dengan kesejahteraan publik (public welfare) yang berada di organisasi atau komunitas. Kegiatan filantropi di dunia Barat dipengaruhi oleh motivasi dan inspirasi keagamaan. Dikatakan bahwa filantropi merupakan konsep universal. Sebagai suatu asas kebaikan, praktek bersedekah, dengan berbagai landasan teologis filosofis dan etis, senantiasa menjadi bagian dari tradisi agama. ${ }^{6}$

Faith based organization (FBO's) yang dimaksud disini ialah organisasiorganisasi sosial (non-profit). Organisasi pada sektor ini bertujuan antara lain untuk memberikan layanan sosial, kebutuhan primer masyarakat, dan menyediakan model advokasi dengan didasarkan sistem kemandirian (selfreliance). ${ }^{7}$ Program filantropi yang dilaksanakan misalnya, pemberdayaan masyarakat, pengentasan kemiskinan, dan bantuan pendidikan non-formal. Pelaksanaan kegiatan seperti ini dengan kerja sama antar FBO's dan negara untuk melahirkan kebijakan kesejahteraan rakyat bermisi pro-rakyat.

${ }^{4}$ M. Dawam Rahardjo, Filantropi Islam dan Keadilan Sosial: Mengurai Kebingunan Epistemologis (Jakarta: Teraju, 2003), xxxiv.

${ }^{5}$ US History Encyclopedia, http://www.answers.com/topic/philatropy (diakses 8/1/2017).

${ }^{6}$ Hilman Latief, Melayani Umat: Filantropi Islam dan Ideologi Kaum Modernis (Jakarta: Gramedia Pustaka Utama, 2010), 35-36.

${ }^{7}$ Hilman Latief, Politik Filantropi Islam, 32. 


\section{ORGANISASI FILANTROPI BERBASIS KEAGAMAAN}

Lembaga filantropi, sebagaimana organisasi sosial lainnya, memiliki target penerima manfaat. Nomenklatur penerima manfaat yang sering dikampanyekan dalam proses penggalangan dana oleh lembaga filantropi, sangat berpengaruh pada karakter program setiap lembaga filantropi, yaitu kaum miskin dan anak-anak terlantar/yatim. ${ }^{8}$ Perubahan sikap dan kebijakan presiden Soeharto menjadi salah satu faktor penting dalam perkembangan filantropi Islam. Soeharto memulai munculnya usaha filantropi Islam yang kemudian terbukti menjadi salah satu lembaga warisan, yaitu yayasan amal bakti muslim pancasila (YABMP) pengoperasiannya memungut dana Rp 1.000 dari setiap PNS dan anggota ABRI beragama Islam, yang digunakan untuk membangun masjid dan kegiatan dakwah. ${ }^{9}$

Menurut Amelia Fauzia, kegiatan filantropi Islam termasuk pembentukan lembaga pendidikan, penyediaan komunitas layanan, atau dukungan keuangan proyek-proyek pembangunan. Hal ini mewakili elemen masyarakat sipil yang kuat dan tumbuh dalam menghadapi negara yang lemah. ${ }^{10}$ Adapun pendapat Max Weber dalam bukunya ekonomi dan masyarakat, alasan berperan dalam konteks aksi sosial, menurutnya aksi sosial adalah tindakan yang berorientasi ke arah perilaku orang lain. Ada empat jenis ideal yaitu, (1) instrumental rasional, berharap hasil sebagai kondisi dan sarana untuk mencapai akumulasi. (2) nilai rasional, menilai tindakan untuk keperluan sendiri terlepas kemungkinan hasilnya sukses. (3) affectual-determinan ditentukan perasaan atau emosi. (4) ditentukan tradisi oleh kebiasaan. Tindakan rasional dan hasil rasional diukur tapi tidak sesuai dengan tindakan yang baik atau tradisi maka nilai- rasional juga akan menjadi irasional. Hal lain juga menunjukkan bahwa perbedaan dalam aksi sosial mungkin timbul dari wilayah yang tingkat partisipasinya berbeda. Weber juga berpendapat bahwa pemberian sedekah merupakan aspek etis setiap agama. ${ }^{11}$

\section{FILANTROPI UNTUK KESEJAHTERAAN SOSIAL DAN KEADILAN SOSIAL}

Sebagai negara muslim terbesar di dunia, Indonesia mengalami proses Islamisasi yang kuat, setidaknya sejak akhir tahun 1990-an - sekarang. Proses Islamisasi yang semakin kental dalam birokrasi negara yang berimplikasi pada dinamika gerakan filantropi Islam. Hal ini sesuai dengan yang disebut oleh

${ }^{8}$ Ibid., 166

${ }^{9}$ Azyumardi Azra, "Negara dan Filantropi Islam", dalam www.republika.co.id, di akses tanggal 8 Januari 2017.

10Dayana Parvanova, Book Review, Amelia Fauzia : Faith and the State: A History of Islamic Philantropy in Indonesia (University of Vienna Austria: ASEAS, 2013), 398.

${ }^{11}$ Erica Bornstein, "The Impulse of Philanthropy" Cultural Anthropology, the America Anthropological Association., Vol. 24, Issues 4, pp. 622-651. 2009, 623-624. 
Arskal Salim dengan 'nasionalisasi Syari'ah' yaitu ditetapkannya kebijakankebijakan institusional zakat, pengelolaan zakat, kewajiban membayar zakat dan pajak, dan sebagainya. Para cendekiawan Muslim mulai memberikan makna yang lebih luas terhadap filantropi Islam bukan hanya aspek keagamaan namun, aspek sosial ekonomi untuk menegakkan keadilan sosial. ${ }^{12}$

Pembangunan kesejahteraan sosial merupakan usaha yang terencana dan terarah yang berbagai bentuk intervensi sosial dan pelayanan sosial untuk memenuhi kebutuhan manusia, mengatasi masalah sosial, dan memperkuat institusi-institusi sosial. ${ }^{13}$ Penanggung jawab utama dalam mengatasi problem sosial yaitu negara melalui kementerian sosial dan kementerian lainnya yang terkait bidang kesejahteraan sosial. Sementara itu, lembaga non pemerintah yang menyelenggarakan kesejahteraan sosial adalah masyarakat, organisasiorganisasi sosial seperti lembaga filantropi.

Pergeseran paradigma pembangunan kesejahteraan sosial akibat perkembangan globalisasi dan menguatnya interaksi antar peradaban dunia telah memperkuat paham ekonomi kapitalisme dalam berbagai pendekatan pembangunan. Berbagai sektor pembangunan terobsesi oleh pendekatan efisiensi, rasionalisasi, dan indikator ekonomi lainnya sehingga sektor kesejahteraan sosial ikut terpengaruh. Secara makro paham ekonomi kapitalisme telah melahirkan kritikan tajam terhadap paham welfare state (negara kesejahteraan). Sehingga berkembang anggapan bahwa negara kesejahteraan merupakan sistem yang boros, tidak mampu memberdayakan masyarakat, dan menimbulkan jebakan kemiskinan. Melalui stigma ini pembangunan kesejahteraan sosial mengalami pergeseran paradigma. Memunculkan dimensi teoritis baru yaitu dari masalah ke kebutuhan, dari stigmasisasi ke hak asasi manusia, dari penerima pasif ke pelaku aktif, dan dari bantuan sosial ke pemberdayaan. ${ }^{14}$

Oleh karena itu, faktor keterbukaan dari unsur pimpinan yang berorientasi kepada kepentingan agama, dan kepentingan negara harus di utamakan untuk menghindari kepentingan diri sendiri. Fokus kepada maqashid syariah adalah sangat di perlukan untuk kesejahteraan masyarakat menurut syariat Islam. Tanpa faktor tersebut sukar dibayangkan terciptanya keadilan sosial melalui pengelolaan filantropi dan hanya akan menjadi sebuah wacana. ${ }^{15}$

\footnotetext{
12Hilman Latief, Politik Filantropi Islam, 15.

${ }^{13}$ Edi Suharto, Analisis Kebijakan Publik Panduan Praktis Mengkaji Masalah dan Kebijakan Sosial (Bandung: Alfabeta, 2012), 35.

${ }^{14}$ Edi Suharto, Analisis Kebijakan Publik, 37

${ }^{15}$ Azyumardi Azra, Berderma Untuk Semua Wacana dan Praktik Filantropi Islam (Jakarta: Mizan Publika, 2003), 39.
} 


\section{PROGRAM POS KEADILAN PEDULI UMMAT (PKPU) SEBAGAI LEMBAGA FILANTROPI}

Kemunculan Pos Keadilan Peduli Ummat (PKPU) sejak krisis yang terjadi pada tahun 1997 yang mempengaruhi kondisi perekonomian bangsa dan rakyat Indonesia. Menyikapi krisis yang berkembang, sejumlah pemuda melakukan aksi sosial di sebagian wilayah Indonesia. Mereka kemudian menggagas entitas kepedulian publik yang bisa bergerak secara sistematis. Maka pada 10 Desember 1999 lahirlah lembaga sosial yang bernama PKPU. Seiring berjalannya waktu lembaga kemanusiaan nasional PKPU telah memperoleh register di PBB sebagai lembaga dengan status "special consultative status" dari economic and social council (Ecosoc). ${ }^{16}$

PKPU adalah sebuah organisasi basis Islam yang telah resmi di akui oleh pemerintah Indonesia. PKPU resmi ditunjuk sebagai organisasi koleksi zakat nasional, berarti pemerintah mengakui sebagai organisasi yang bertanggung jawab untuk mengelola dan mendistribusikan zakat, infak, sedekah, dan wakaf di Indonesia. ${ }^{17}$ PKPU mempunyai hubungan sejarah dengan Partai Keadilan Sejahtera (PKS). PKPU berada di bawah struktur organisasi PKS dan di kenal sebagai Pos Terpadu Pelayanan Masyarakat (poster masyarakat). Pada tahun 1999 PKPU menjadi organisasi independen yang mengelola dana filantropi dari orang Indonesia yang bermukim di dalam dan luar negeri. ${ }^{18}$

PKPU memiliki sejumlah program di berbagai sektor yaitu, pendidikan, ekonomi, tanggap darurat, kesehatan, sosial, dan yatim. Keseluruhan aktivitas tersebut didedikasikan pada umat dan rakyat Indonesia untuk bersama. PKPU berkeyakinan bahwa yang terbaik diantara mereka adalah yang paling besar kontribusinya terhadap sesama. Aksi nyata program prioritas filantropi PKPU adalah sebagai berikut ${ }^{19}$ :

a. Penanggulangan bencana berbasis komunitas (Community Based Disaster Risk Management) tujuan program ini adalah mendorong masyarakat untuk mandiri dalam menghadapi resiko bencana.

b. Program Ibu Sadar Gizi (BUDARZI) program ini ditujukan kepada masyarakat yang mempunyai anak balita dalam rangka peningkatan gizi anak. Karena itu, yang menjadi sasaran utama adalah ibu-ibu kurang mampu yang memiliki anak balita.

16PKPU, "Sejarah PKPU", dalam http://www.pkpu.org/about-us/history/, di akses tanggal 8 Januari 2017.

${ }^{17}$ Dede Rusdiana dan Zaim Saidi, Diaspora giving: An Agent of Change in Asia Pacific Communities (Indonesia: AsiaPacific Philantrophy Consortium, 2008), 167.

18 Ibid., 169.

${ }^{19}$ Widyawati, Filantropi Islam dan Kebijakan Negara Pasca-Orde Baru : studi tentang Undang-Undang Zakat dan Undang-Undang Wakaf (Bandung: Arsad Press, 2011), 160-161. 
c. Program komunitas sehat. Program ini fokusnya adalah pemberian layanan kesehatan bagi masyarakat miskin.

d. Program Komunitas Hijau (Green Comuunity) yaitu program pemberdayaan masyarakat dengan orientasi pada kesehatan.

e. Program Sinergi Pemberdayaan Komunitas (PROSPEK) adalah program yang berorientasi pada masyarakat dalam bidang ekonomi usaha kecil/UMKM.

f. Program Pendidikan Berbasis Potensi Masyarakat. Program yang ditujukan dalam mengasah kemampuan yang dimiliki oleh masyarakat agar memiliki motivasi yang kuat, pengetahuan, dan keterampilan yang dapat dikontribusikan bagi pengembangan daerah.

g. Voucher Yatim, yaitu program filantropi dalam bentuk voucher belanja yang diberikan kepada anak-anak yatim sesuai kebutuhan mereka.

h. Dan beberapa program kerjasama antar lembaga filantropi, kemanusiaan, pembangunan masyarakat, dan pengumpulan dana.

Sebuah babak baru bagi PKPU, dimana keberadaannya sebagai lembaga kemanusiaan nasional juga diakui internasional. Tekad PKPU untuk bekerja atas nama kemanusiaan lintas negara diakui secara profesional. Kerja nyata itu terwujud dalam program kemanusiaan untuk gempa Haiti, gempa Turki, gemopa Jepang, krisis kemanusiaan di Somalia, Palestina, Philipina, Palestina, dan krisis kemanusiaan di Myanmar. Sebagai lembaga sosial yang menangani peristiwa kemanusiaan global maka PKPU mengembangkan standarisasi program dengan peningkatan mutu program dan layanan dengan menghasilkan kontribusi yang solutif bagi masyarakat. ${ }^{20}$

PKPU membuka donasi bagi masyarakat yang ingin menyumbangkan uang untuk realisasi program. Bagi masyarakat yang ingin berdonasi bisa melalui rekening kemanusiaan PKPU di berbagai bank yang bekerjasama dengan PKPU atau cara kredit melalui log-in pada halaman web PKPU. Cara berdonasi dapat melalui transfer, tunai, atau fasilitas payment online di situs PKPU Human Initiative. Pihak PKPU menyediakan layanan langsung via telepon, whatss app (WA), dan email apabila calon donatur mengalami kesulitan saat melakukan donasi atau ingin melakukan pertanyaan.

PKPU tidak hanya fokus berbagi bantuan di Indonesia. Namun, bantuan kemanusiaan PKPU diberikan juga ke berbagai negara yang dilanda bencana. Pada maret 2017 lembaga PKPU mengirimkan tim misi kemanusiaan ke Somalia, Kenya, dan Nigeria. Pengiriman tim tersebut sebagai bentuk 
kepedulian atas bencana kelaparan, kekeringan, dan wabah penyakit kolera yang menimpa warga di ketiga negara tersebut. ${ }^{21}$

\section{TRANSFORMASI PKPU DARI LEMBAGA KEMANUSIAAN NASIONAL KE HUMAN INITIATIVE : WACANA DAN AGENDA KERJA}

Pada Milad PKPU ke-17 diluncurkan logo barunya yaitu "PKPU Human Initiative". Presiden Direktur PKPU, Agung Notowigono, mengatakan, PKPU berkomitmen melakukan bantuan kemanusiaan yang jauh lebih luas dari sebelumnya. Human Initiatve ingin lebih mengumpulkan inisiatif-inisiatif kebajikan seluruh manusia, baik dari Indonesia sampai negara lainnya untuk kemanusiaan.

Dalam berbagai bencana dan konflik dibeberapa belahan dunia, keberadaan organisasi kemanusiaan untuk membantu korban bencana sangat kuat. Inisiatif masyarakat sipil tentunya sangat berperan dalam lembaga kemanusiaan. Pertumbuhan organisasi kemanusiaan Islam berpengaruh terhadap pembentukan wacana dan agenda misi kemanusiaan. ${ }^{22}$ Jangkauan organisasi Islam yang ikut terlibat dalam pekerjaan sosial dan kemanusiaan sangat luas. Peranan yang dimainkan sangat mencolok, mereka membagikan makanan dan pakaian kepada anak yatim piatu dan kaum miskin, sembari menyediakan pelayanan kesehatan dan pendidikan, pemberdayaan masyarakat miskin, dan memberikan bantuan untuk korban bencana. ${ }^{23}$

Selain program-program di berbagai sektor, PKPU memiliki tiga program baru yang sedang dikerjakan tahun 2017. Adapun program-program tersebut adalah initiative for children (program yang berrtujuan meningkatkan pengetahuan dan keterampilan anak yatim), initiative for disaster (program yang bertujuan untuk mengurangi dampak bencana melalui pemberdayaan masyarakat), dan initiative for empowerement (program pemberdeyaan untuk meningkatkan kualitas hidup, kemandirian, serta kesejahteraan masyarakat berkelanjutan). ${ }^{24}$

Telah di jelaskan sebelumnya, terdapat agenda baru dari programprogram PKPU Human Initiative. Agenda tersebut fokus ke pemberdayaan masyarakat kurang mampu dan bantuan kepada anak yatim, serta bantuanbantuan bagi daerah bencana. Transformasi PKPU merupakan gerakan baru

\footnotetext{
21Sindonews, "Afrika Dilanda Kelaparan, PKPU Berangkatkan Tim ke Benua Hitam,” dalam https://nasional.sindonews.com/read/1189939/94/afrika-dilanda-kelaparan-pkpuberangkatkan-tim-ke-benua-hitam-1489995365, diakses pada 30 Juli 2017.

${ }^{22}$ Hilman Latief dan Zezen Zaenal Mutaqin, "Islam dan Urusan Kemanusiaan: Peta Wacana dan Perumusan Agenda Kerja", Hilman Latief dan Zezen Zaenal Mutaqin (ed.), Islam dan Urusan Kemanusiaan: Konflik, Perdamaian, dan Filantropi (Jakarta: Serambi, 2015), 23-24.

${ }^{23}$ Hilman Latief, Melayani Umat: Filantropi, xvi. Juli 2017.

${ }^{24}$ PKPU, "Program human initiative," dalam https://www.pkpu.org, diakses pada 30
} 
yang memunculkan agenda baru dalam perannya dalam mengatasi masalah kemanusiaan.

\section{PENUTUP}

Aktifitas filantropi berbasis keagamaan telah ada bukan hanya agama Islam tapi juga agama-agama lainnya. Filantropi Faith based organization beroperasi dalam memberikan pelayanan dan bantuan sosial kepada masyarakat guna mengatasi permasalahan sosial. Perubahan sikap dan kebijakan presiden Soeharto menjadi salah satu faktor penting dalam perkembangan filantropi Islam di Indonesia. Salah satu lembaga filantropi di dunia adalah Pos Keadilan Peduli Ummat (PKPU) yang memiliki program aksi nyata seperti pengumpulan dana, pemberdayaan masyarakat, pembangunan masyarakat, pelayanan bantuan sosial, bantuan kemanusiaan. PKPU sebagai lembaga nasional juga diakui secara internasional dari Ecosoc. Dalam pandangan Islam telah jelas bahwa Islam menolak teori kapitalisme yang melakukan akumulasi kapital dan bebas memberikan hartanya kepada siapa saja yang dia kehendaki, bebas melakukan tabungan, dan menghaburkan untuk aktivitas tertentu.

Seiring berjalannya waktu, lembaga kemanusiaan PKPU mengembangkan program-programnya. PKPU Human Initiative berkomitmen memberikan bantuan kemanusiaan terhadap korban bencana, pemberdayaan masyarakat kurang mampu, bantuan kepada anak yatim. PKPU menyalurkan bantuan di berbagai daerah di Indonesia dan negara-negara yang ada di dunia.

\section{DAFTAR PUSTAKA}

Azra, Azyumardi. "Negara dan Filantropi Islam.”, dalam www.republika.co.id. Diakses 8 Januari 2017.

Berderma Untuk Semua Wacana dan Praktik Filantropi Islam, Jakarta: Mizan Publika, 2003.

Bornstein, Erica. "The Impulse of Philanthropy" Cultural Anthropology, the America Anthropological Association., Vol. 24, Issues 4, pp. 622-651. 2009.

Latief, Hilman. Politik Filantropi Islam di Indonesia, Yogyakarta: Ombak, 2013. Melayani Umat: Filantropi Islam dan Ideologi Kaum Modernis, Jakarta: Gramedia Pustaka Utama, 2010.

Latief, Hilman dan Zezen Zaenal Mutaqin, "Islam dan Urusan Kemanusiaan: Peta Wacana dan Perumusan Agenda Kerja", Hilman Latief dan Zezen Zaenal Mutaqin (ed.), Islam dan Urusan Kemanusiaan: Konflik, Perdamaian, dan Filantropi. Jakarta: Serambi, 2015.

Maryolo AR, Amril. "Review artikel Hilman Latief (Philantrophy and Muslim Citizenship in Post-Suharto Indonesia)" Tugas review artikel dalam mata kuliah Topik Khusus Agama dan Masyarakat di Pps UIN Sunan Kalijaga Yogyakarta, tanggal 21 November 2016. 
Parvanova, Dayana. Book Review, Amelia Fauzia : Faith and the State: A History of Islamic Philantropy in Indonesia, University of Vienna Austria: ASEAS, 2013.

PKPU, "PKPU diakui Sebagai NGO in Special Consultative Status with Economic Social Council at United Nation" Annual Report PKPU 2009-2013 (Indonesia).

"Sejarah PKPU", http://www.pkpu.org/about-us/history/. Diakses tanggal 8 Januari 2017.

,"Program human initiative," dalam https://www.pkpu.org, diakses pada 30 Juli 2017.

Rahardjo, M. Dawam. Filantropi Islam dan Keadilan Sosial: Mengurai Kebingunan Epistemologis, Jakarta: Teraju, 2003.

Sindonews, "Afrika Dilanda Kelaparan, PKPU Berangkatkan Tim ke Benua Hitam,"

dalam

https://nasional.sindonews.com/read/1189939/94/afrika-dilandakelaparan-pkpu-berangkatkan-tim-ke-benua-hitam-1489995365, diakses pada 30 Juli 2017.

Suharto, Edi. Analisis Kebijakan Publik Panduan Praktis Mengkaji Masalah dan Kebijakan Sosial, Bandung: Alfabeta, 2012.

US History Encyclopedia, http://www.answers.com/topic/philatropy. Diakses 8 Januari 2017.

Widyawati, Filantropi Islam dan Kebijakan Negara Pasca-Orde Baru : studi tentang Undang-Undang Zakat dan Undang-Undang Wakaf, Bandung: Arsad Press, 2011.

Yusuf Al-Qardhawi, Muhammad. Musykilatul Fakri Wa-Kaifa 'Alajahal Islam. Umar Fanany (terj.). Surabaya: Bina Ilmu, 1996. 